\title{
Factors licensing embedded present tense in speech reports ${ }^{1}$
}

Corien BARY — Radboud University Nijmegen

Daniel ALTSHULER - Hamspire College/UMass Amherst

Kristen SYRETT - Rutgers University - New Brunswick

Peter DE SWART — Radboud University Nijmegen

\begin{abstract}
According to Ogihara (1995), the usage of the embedded present in a speech report such as John said that Mary is in the room is restricted by the cause of John's belief (the state that made John think that Mary is in the room): the present tense can be used only if this cause still holds at the time that John said that Mary is in the room is uttered. This paper presents experimental evidence demonstrating that this is only one of the factors that licenses a felicitous usage of the embedded present tense. In particular, we show that the cause of belief still holding is not a necessary condition, and identify two additional, sufficient (but not necessary) factors: in cases of false belief, who is aware of the falsity of the belief and duration of the reported state. While these factors are independent, they collectively support the idea that the present tense encodes 'current relevance', even in embedded contexts (e.g. Costa 1972; McGilvray 1974). This gives rise to the question of how we can derive 'current relevance' and, in particular, whether previous analyses of the embedded present tense are adequately equipped to do so.
\end{abstract}

Keywords: tense, speech reports, double access, experiments.

\section{Introduction: present under past}

The question this paper addresses is the following: when can we use a present tense in the complement of a past tense speech report? An example of such a construction is in (1):

(1) John said that Mary is in the room.

Ogihara (1995) claimed that the truth of the complement at the actual utterance time $n$ (the time when (1) is uttered) is not a prerequisite for the use of an embedded present tense. What matters instead is the cause of the belief (the state that made John think that Mary is in the room, e.g. the presence of someone who looks like Mary). More precisely, Ogihara's observation was that the present tense can only be used if this cause still holds at $n$. We refer to this as the KEY OBSERVATION since it has motivated various analyses of embedded tense (e.g. Abusch 1988, 1997; Ogihara 1995; Heim 1994). Recently, however, the KEY OBSERVATION has been called into question by Klecha (2015), who comes with the following scenario:

(2) Mary puts a balloon under her shirt. John then observes her in this state, and then says to everyone: 'Mary is pregnant!' Later that day, Mary takes the balloon out from under her shirt and pops it. Bill, aware of everything that happened, says to Mary: '(Earlier today,) John told everyone that you're pregnant.'

\footnotetext{
${ }^{1}$ We would like to thank the participants of Sinn und Bedeutung 22, XPrag 2017 and the Oslo Theoretical Linguistics Seminar for their comments. The research for this paper is supported by the EU under FP7, ERC Starting Grant 338421-PERSPECTIVE (Bary).
} 
In this scenario, the cause of John's belief that Mary is pregnant, i.e. the state of the balloon under her shirt, is absent by the time of Bill's report. Nevertheless, the present tense is acceptable, suggesting that the KEY OBSERVATION is empirically inadequate.

This difference leads us to ask what exactly it is that licenses the embedded present tense and whether, if it turns out that more than one factor plays a role, this bundle of factors are unified by, and are the instantiation of, an underlying factor. To make headway in addressing these questions, we conducted two experiments (a rating task and a forced choice task) that manipulate such factors and aim to precisify the empirical basis for the use of the embedded present tense. Our starting point is in the comparison of the minimal differences between Ogihara's and Klecha's scenarios, which give rise to the factors we manipulate: (i) the choice of a particular embedding verb of reporting, (ii) in cases that involve false belief, who is aware of the falsity of the belief, and (iii) the duration of the reported state. Our experimental findings indicate that while (i) does not appear to have an influence, factors (ii) and (iii) do. We propose that - along with the KEY OBSERVATION-(ii) and (iii) collectively support the idea of "current relevance' (Costa 1972; McGilvray 1974), thereby giving rise to the question of whether and how previous analyses of the embedded present tense are adequately equipped to derive 'current relevance'.

The structure of the paper is as follows: In section 2 we further outline the historical and theoretical background to our experiments. In particular, we discuss the scenarios that led Ogihara to his KEY OBSERVATION, as well as Klecha's example noted above. In comparing the data, we motivate two experiments, which we discuss in section 3. Finally, in section 4 we discuss the consequences of our experiments for previous analyses of the embedded present tense.

\section{Background: Ogihara's key observation and Klecha's counterexample}

Much research in the past decades has been devoted to providing adequate felicity conditions for the use of the present tense in past tense speech reports. ${ }^{2}$ When comparing (1) with its past tense counterpart in (3), the idea has been since the 70s that the embedded present tense imports additional information (e.g. Smith 1978):

(1) John said that Mary is in the room.

(3) John said that Mary was in the room.

While both the present and past tense lead to an inference in which according to John, Mary was in the room at the time that John locates himself at the time of his utterance, only the embedded present tense imposes a requirement about the actual utterance time $n$. This additional requirement has lead to the name double access (Enç 1987), describing an interpretation of (1) that involves reference to two times (the time John locates himself and the actual utterance time $n)$.

\footnotetext{
${ }^{2}$ See Klecha, this volume for discussion.
} 
In the nineties, Ogihara and Abusch independently tried to make clearer what exactly it is that has to hold at the actual utterance time for the present tense to be felicitous. Ogihara (1995) considers various contexts for (1):

(4) John and Bill are looking into a room. Sue is in the room.

John (near-sighted): 'Look! Mary is in the room.'

Bill: 'What are you talking about? That's Sue, not Mary.'

a. John: 'I'm sure that's Mary.'

One minute later, Kent joins them. Sue is still in the room.

Bill (to Kent): 'John said that Mary is in the room. But that's not true. The one that is in the room is Sue.'

b. John: 'Yeah. You're right. That's Sue.'

One minute later, Kent joins them. Sue is still in the room.

Bill (to Kent): 'John said that Mary is in the room.'

c. John: 'I'm sure that's Mary.'

Sue leaves the room. One minute later, Kent joins them.

Bill (to Kent): \# 'John said that Mary is in the room.'

On the basis of (4a), Ogihara concludes that the truth of the complement at the actual utterance time is not a prerequisite for the use of a present tense: Mary is not in the room, but still a present tense in the complement is acceptable. Moreover, based on (4b), Ogihara argues that it also doesn't matter whether the reported speaker (John) has found out the truth of the complement at some point after his utterance. By the time of the report, John no longer believes that Mary is in the room, but again the present is still acceptable. Comparing (4a) and (4b) (where Sue is still in the room) with (4c) (where Sue has left), Ogihara concludes that if the state that made John think that Mary is in the room still holds at the actual utterance time $n$, then we can use the present tense. Otherwise, we cannot. As mentioned in section 1, we call this the KEY OBSERVATION.

Without going into too much detail, let us say a bit on the formal-semantic implementation of this observation, which we come back to in section 4. In Ogihara's words, the truth conditions of (1) are as follows: (1) is true iff there exists a state $s$ at the actual utterance time $n$ such that John talks at the reported time in the past as if he ascribes to $s$ the property of being a state of Mary's being in the room (Ogihara, 1995: 205). Note that this state $s$ has to hold at $n$. In (4a) and (4b), but not in (4c), there is such a state still holding, namely Sue's being in the room. This predicts correctly that (4a) and (4b) are acceptable, in contrast to (4c).

Ogihara thus proposes that (4) is an example of de re reports about states: John makes an utterance about a state which happens to hold at the actual utterance time, without this moment (which is in the future for him) playing a role in his mind. Building on Cresswell and von Stechow's (1982) analysis of de re reports about individuals, Ogihara then formalises such de $r e$ reports about states in terms of acquaintance relations: (1) is true iff there exists a state $s$ at the utterance time $n$ and a suitable acquaintance relation $R$ such that: (i) $s$ is the state to which John bears $R$ in the actual world and time of his utterance; and (ii) John talks at this time as if in all belief alternatives, $s$ has the property of Mary's being in the room. In (4a) and (4b) there 
is such a state that satisfies these requirements, namely the state of Sue's being in the room, to which John is acquainted via the relation "the situation that I am observing". 3

Let us leave this theoretical implementation aside for the moment and return to the KEY OBSERVATION that has driven this implementation. Recall that the KEY OBSERVATION is as follows: as long as the cause of the belief is still present at the actual utterance time $n$, the present tense is felicitous; otherwise it isn't. As noted in the previous section, Klecha (2015) questions this KEY OBSERVATION with the example in (2), repeated below:

(2) Mary puts a balloon under her shirt. John then observes her in this state, and then says to everyone: 'Mary is pregnant!' Later that day, Mary takes the balloon out from under her shirt and pops it. Bill, aware of everything that happened, says to Mary: '(Earlier today,) John told everyone that you're pregnant.'

In this scenario, the cause of John's belief that Mary is pregnant, i.e. the state of the balloon under her shirt, is absent by the time of Bill's report. Nevertheless, the present tense is acceptable, suggesting that the KEY OBSERVATION is empirically inadequate. The noted formal implementation of this observation, however, has some wiggle room. For example, Abusch (p.c.), who uses acquaintance relations to times rather than states, suggests that the acquaintance relation in (2) could pick out the day in which the attitude time (rather than the time of the balloon being under Mary's shirt) is included, and since this day still holds at the actual utterance time the present tense is acceptable. ${ }^{4}$ While this would allow us to account for (2), the question, then, is why we don't have this flexibility for the infelicitous (4c). To make headway in answering this question, we need to have a better understanding of the factors licensing a felicitous usage of the embedded present, something that is lacking at this moment. Only then will we know what a theoretical analysis should account for, and only then can we start to discuss whether analyses in terms of acquaintance relations are on the right track.

A direct comparison of (2) and (4c) reveals a key set of factors that might play a role in the acceptability of the embedded present tense: the use of tell in (2) versus say in (4c), the duration of the state in the complement, i.e. pregnancy in (2) versus being in a room in (4c), and whether or not the audience of the reported utterance still believes the complement at the time of the report (as is the natural interpretation in (2) but not in (4c)). In the next section we present two experiments that test these three factors. We return to the theoretical discussion in section 4 .

\section{Experiments}

We conducted two complementary experiments to investigate the factors licensing the use of the embedded present tense, targeting precisely those types of cases of interest to Ogihara and later Klecha, where the target sentence reports a false belief. We further zoomed in on one those cases in which the cause of the belief no longer holds at the speech time. Both experiments used

\footnotetext{
${ }^{3}$ We find very similar insights in Abusch 1997 and Heim 1994 (a reformulation of Abusch 1994), with the difference that Abusch uses acquaintance relations to intervals rather than states, while Heim uses time concepts: the meaning of descriptions by which a speaker might represent a time to herself, technically a function from world time pairs to times.

${ }^{4}$ Note that it is less clear whether Ogihara's acquaintance relation that picks out states could be manipulated along these lines.
} 
a similar design, differing primarily in the behavioral response requested of the participants.

\subsection{Experiment 1: rating task}

Participants Eighty-eight native English speakers, all undergraduates at Rutgers University - New Brunswick, participated. They were granted extra credit in a Linguistics or Cognitive Science course for participating. The age range of the participants was 17 to 32 years.

Design The experiment followed a fully-crossed $2 \times 2 \times 2 \times 3$ design (see Table 1 for an overview). There were two between-subject factors (TENSE OF EMBEDDED VERB (past vs. present) and MATRIX VERB (say vs. tell)), and two within-subject factors (DURATION OF THE REPORTED PROPERTY (short term vs. long term)) and WHO WAS AWARE of the fact that it was a false belief at the time of the report (A: the reporter alone; $\mathrm{B}$ : the reporter and the reported speaker; C: the reporter, the reported speaker, and the audience)).

Factor

EMBEDDED TENSE

(between subjects, within items)

MATRIX VERB

(between subjects, within items)

DURATION OF THE REPORTED PROPERTY

(within subjects, between items)

WHO IS AWARE OF THE FALSITY

(within subjects, within items)

\section{Levels}

present, past

tell, say

short-term, long-term

A: reporter

B: reporter, reported speaker

C: reporter, reported speaker, original audience

Table 1: Factors manipulated in Experiment 1

Stimuli We constructed 12 experimental scenarios for the test items. Among these 12, six items featured a short-term property (e.g. being in a bar), and six featured a long-term property (e.g. being pregnant). Within each of these there were two items each of the 'who was aware' factor levels, yielding four of each. Three versions of every test item were made reflecting the levels of the 'who was aware' factor. These were then fed into a Latin Square design.

Scenarios were structured in the following way: Each scenario began with the introduction of two key individuals ('Ind-1' and 'Ind-2') and some friends, the 'Audience'. There were ultimately four individuals plus the audience in the scenario, whose designated roles were linked to the target sentence uttered at the end of the trial (Ind-1: Reporter; Ind-2: Reported Speaker; 
Ind-3: Subject of the Belief; Ind-4: Friend who the target sentence is going to be told to). In order to facilitate comprehension, the characters were given names whose alphabetical order reflected their order of introduction (e.g., Janelle, Keisha, Latasha, Meghan; Alex, Bill, Cindy, Dana).

A scenario was setup as follows. Ind-2 remarks aloud to Ind-1 that an 'Ind-3' has a long or short term property $P$. This utterance is in fact false. Ind-1 knows this but the exclamation is acknowledged as true by the Audience at this point. The scenario then diverges based on who becomes aware of this falsity in three conditions, all three of which were seen by a single participant, across different scenarios:

(A) Ind-1 remarks to Ind-2 out of earshot that the claim is false. Ind-2 holds fast to the original claim, and departs from the situation, leaving only the Reporter (Ind-1) to be aware of the falsity.

(B) Ind-1 remarks to Ind-2 out of earshot that the claim is false. Ind-2 then realizes the falsity of the original claim, mentioning this to Ind-1, leaving both the Reporter (Ind-1) and the Reported Speaker (Ind-2) aware of the falsity.

(C) Ind-1 remarks to Ind-2 in front of the Audience that the claim is false. Ind-2 then realizes the falsity of the original claim, mentioning this to Ind-1 in front of the Audience, leaving the Reporter (Ind-1), the Reported Speaker (Ind-2), and the Audience aware of the falsity.

Then in all experimental items, the state that was the cause of the false belief ceases to hold, but only those individuals who recognized the falsity of the belief above witness this change (Ind-1 in (A), Ind-1+2 in (B), and Ind-1+2 and Audience in (C)).

All scenarios were resolved in the same way: another individual (Ind-4, the Friend, not part of the original Audience) arrives a few minutes later. Ind-1 reports Ind-2's original claim to Ind-4 (hence, the role of Reporter and Reporter Speaker), saying, "Ind-2 [said/told us] that [Ind-3 VP]." Participants were asked to respond to this target sentence, given the scenario they had just read.

Examples of two experimental items (one with a short-term property and one with a long-term property) are provided in (5) and (6), with the target sentence in bold face.

\section{Short-term property}

Alex, Bill, and some other friends are hanging out. Alex and Bill both look into a room. Cindy is in the room. But Alex is near-sighted and can't see that well. He turns to Bill, in earshot of the others, and says, "Look! Dana is in the room." Everyone but Bill nods in agreement.

(A) Bill pulls Alex off to the side, away from the others and replies, "What are you talking about? That's Cindy, not Dana!" Alex says, "No, I'm sure that's Dana." Alex walks away. Bill remains standing there, apart from the others. Bill watches as Cindy leaves the room. No one else sees this. 
(B) Bill turns to Alex in front of the others in the room and replies, "What are you talking about? That's Cindy, not Dana." Alex says, "Oh yeah, you're right! That's Cindy." Alex and Bill remain standing there, apart from the others. Alex and Bill watch as Cindy leaves the room. The others in the room don't see this.

(C) Bill turns to Alex in front of the others in the room and replies, "What are you talking about? That's Cindy, not Dana." Alex says, "Oh yeah, you're right! That's Cindy." Alex, Bill, and all their friends have a good laugh about this. Everyone watches as Cindy leaves the room.

A few minutes later, Bill's friend Edward arrives. Bill says to Edward, "You won't believe this. Alex [said/told us] that Dana [is/was] in the room."

\section{Long-term property}

Marsha, Nadia, and some other girls are waiting for their gymnastics practice to start. They've been told that there's a new girl on their gymnastics team named Olivia. Marsha spots her across the gym, by the uneven bars, but since Olivia is so far away, Marsha can't see that that she is standing on a stool. Marsha says in front of the other girls, "Wow, Olivia is really tall!" All the other girls, except Nadia, have a look and nod in agreement.

(A) Nadia brings Marsha over to stretch with her away from the others and says, "What are you talking about? Olivia is not tall! She's standing on something." Marsha says, "No way, I can see her from here, and Olivia's really tall." Marsha goes off to get her ankles and wrists wrapped before practice. Marsha stays there stretching on her own. Nadia watches as Olivia gets off the stool, and is the same height as the other girls around her. No one else sees this.

(B) Nadia brings Marsha over to stretch with her away from the others and says, "What are you talking about? Olivia is not tall! She's standing on something." Marsha moves to get a better angle, and says, "Oh my gosh, you're right! She is standing on something! She's not really tall!" Marsha and Nadia remain stretching, and wait to re-join the others. Marsha and Nadia watch as Olivia gets off the stool, and is the same height as the other girls around her. No one else sees this.

(C) Nadia turns to Marsha in front of the others and says, "What are you talking about? Olivia is not tall! She's standing on something." Marsha moves to get a better angle, and says, "Oh my gosh, you're right! She is standing on something! She's not really tall!" All of the girls giggle about Marsha's mistake. All the girls watch as Olivia gets off the stool, and is the same height as the other girls around her.

A few minutes later, Nadia's friend Patricia arrives at gymnastics practice. Nadia says to Patricia, "You won't believe this. Marsha [said/told us] that Olivia [is/was] really tall."

The test items were pseudorandomized along with six control items, which shared a similar structure. The control items (three long-term and three short-term properties) had the cause of the belief present.

In addition, three practice scenarios were constructed and eight filler items were included that followed a similar make up as the experimental scenarios but contained other types of target 
sentences (adverbial and embedded clauses), including clear unacceptable ones.

Materials were divided over 12 stimuli lists, following a Latin square design.

Procedure Participants were tested in a laboratory at individual stations. The entire experimental session lasted approximately 25-30 minutes. The experiment began with a brief 3-item training session to acclimate participants to the task.

Stimuli were presented on an iMac using Superlab 4.5 software, in randomized order. Each subsequent aspect of the scenario (introduction of the scenario, exchange between the individuals, etc.) was presented sequentially on the screen, with participants pressing buttons to advance through the scenario at their own pace.

After the target sentence was shown on screen, participants were asked to rate the acceptability of the target sentence on a 5-point scale, ranging from 1 to 5 with: 1: not acceptable at all, 2: hardly acceptable, 3: moderately acceptable, 4: acceptable, 5: definitely acceptable. 'Acceptability' was defined as whether or not a native speaker of English would express the sentence in the way presented. Participants were told that, "A native speaker of English is someone who has known English since childhood. This person may not actually have been born in this country. This person's parents may not speak English. However, this person is considered to be a fluent speaker of English, and could provide judgments about English sentences as a fluent speaker if asked to do so." Participants were also explicitly told that the person who delivered the target statement was always speaking truthfully, and so this sentence is always true, but the participants were asked to focus on whether or not it was ok for the speaker to say it in this way and rate acceptability.

Results Acceptability ratings were converted to z-scores to control for variability in scale use. The resulting scores were analyzed with generalized linear mixed models using the lmerTest package in R (Kuznetsova et al., 2015). Models were fitted the maximal random effects structure justified by the data. Factors were entered into the model using sum coding. Due to the complexity of the design and small numbers of items per condition, we only report effects of individual factors and their interaction with the factor TENSE OF EMBEDDED VERB.

EMBEDDED TENSE: Figure 1 shows the overall scores for target sentences in the present tense $(M=.13, S D=.82)$ and in the past $(M=.21, S D=.79)$. A model with EMBEDDED TENSE as a fixed factor and a random intercept for PARTICIPANT and a random intercept with random slope for ITEM revealed no significant difference. Note that, when looking at the raw scores, both types of sentences seem to be rated as acceptable (PRS: $M=3.82, S D=1.43$; PST: $M=$ 4.02, $S D=1.34)$.

MATRIX VERB: The results for MATRIX VERB are shown in Figure 2. A model with the interaction between MATRIX VERB and EMBEDDED TENSE as fixed factors and a random intercept for PARTICIPANT and a random intercept with random slopes for the two fixed factors for ITEM 


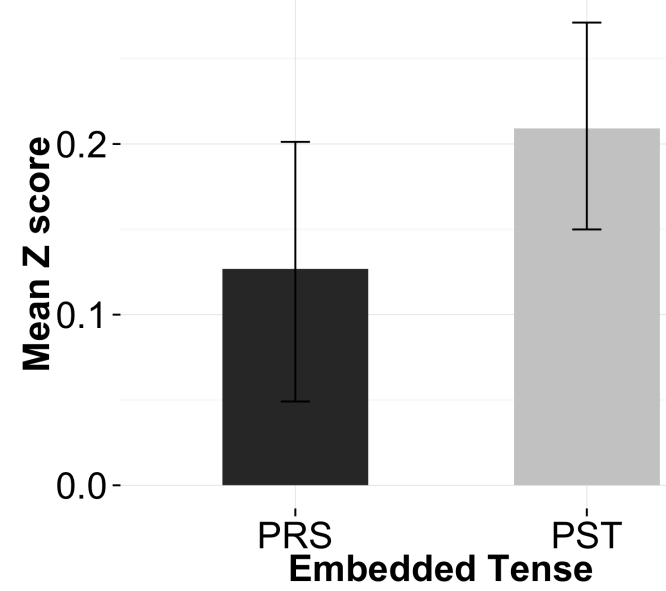

Figure 1: Mean z-scores of acceptability ratings from Experiment 1 for EMBEDDED TENSE, error bars show $95 \% \mathrm{CI}$.

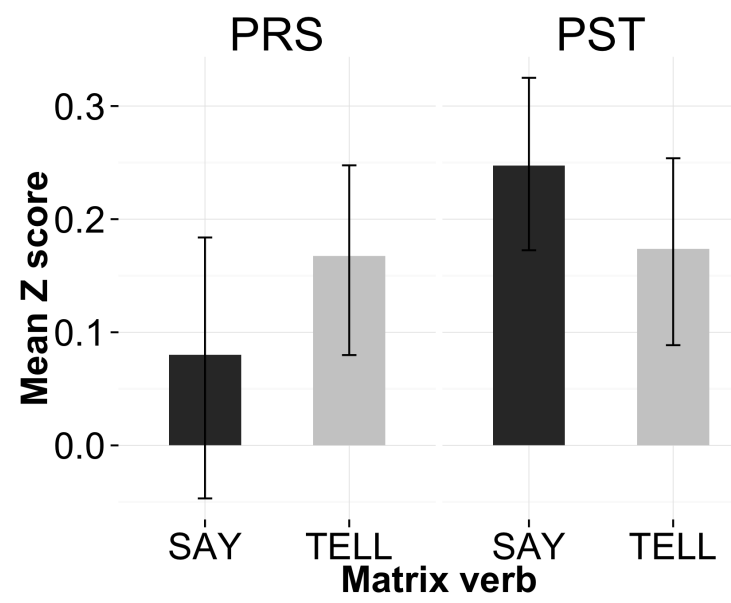

Figure 2: Mean z-scores of acceptability ratings from Experiment 1 for MATRIX VERB, error bars show $95 \% \mathrm{CI}$.

revealed no significant effects.

DURATION OF THE REPORTED PROPERTY: The results for this factor are shown in Figure 3. The findings suggest that the effect of this factor is different in target sentences with present tense compared to those with past tense. A model with the interaction between DURATION OF THE REPORTED PROPERTY and EMBEDDED TENSE as fixed factors and random intercept and random slope of DURATION for PARTICIPANT and a random intercept with a random slope of EMBEDDED TENSE for ITEM revealed a significant interaction $(\beta=.115, S E=.04, t=2.93$, $p=.009)$. A follow-up analysis of simple effects revealed a significant effect of EMBEDDED TENSE on the rating of short-term properties. Short-term properties were rated significantly lower in sentences with embedded present tense $(M=.01, S D=.84)$ than in those with past tense $(M=.33, S D=.75 ; \beta=-.156, S E=.05, t=-3.47, p=.004)$. 


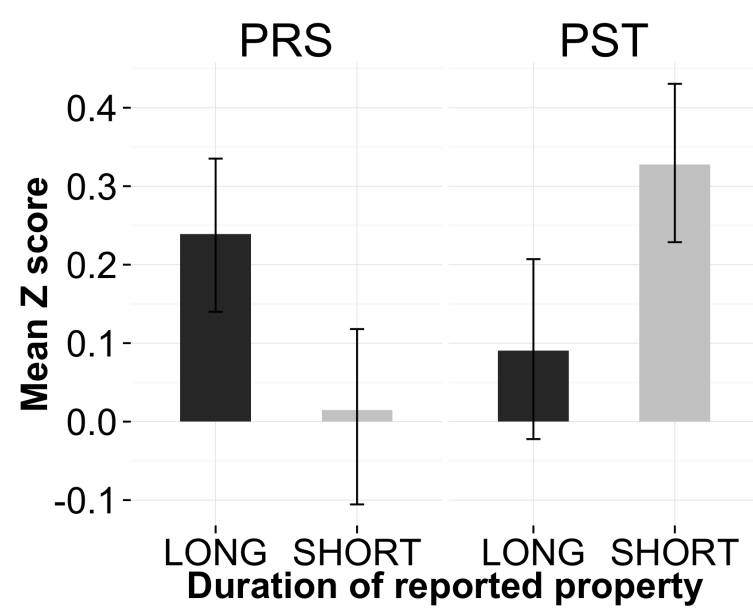

Figure 3: Mean z-scores of acceptability ratings from Experiment 1 for DURATION OF REPORTED PROPERTY, error bars show $95 \%$ CI.

WHO IS AWARE OF THE FALSITY: Figure 4 shows the scores for WHO IS AWARE OF THE FALSITY. The judgments show a lot of variation. The maximally converging model with the interaction between WHO IS AWARE OF THE FALSITY and EMBEDDED TENSE as fixed factors and random intercept and random slope of WHO IS AWARE OF THE FALSITY for PARTICIPANT and a random intercept with a random slope of WHO IS AWARE OF THE FALSITY and EMBEDDED TENSE for ITEM revealed a significant interaction effect $(\beta=.087, S E=.04, t=2.24, p=$ .028). A follow up analysis of simple effects revealed a significant effect of EMBEDDED TENSE on the rating of sentences in which the reporter, the reported speaker and audience are all aware of the falsity (level C) in a model with the maximal random structure. These sentences were rated significantly lower with embedded present tense $(M=.004, S D=.87)$ than with past tense $(M=.31, S D=.76 ; \beta=-.137, S E=.006, t=-2.27, p=.04)$.

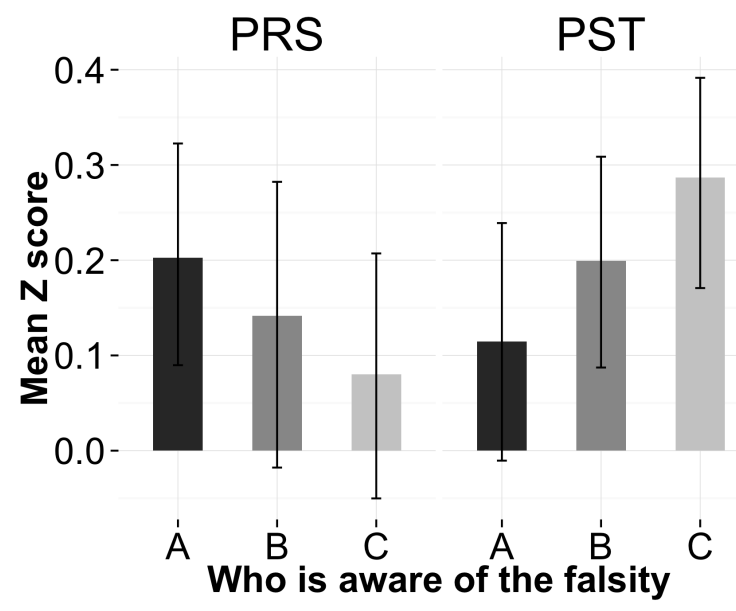

Figure 4: Mean z-scores of acceptability ratings from Experiment 1 for WHO IS AWARE OF THE FALSITY (A: the reporter alone; B: the reporter and the reported speaker; C: the reporter, the reported speaker, and the audience), error bars show 95\% CI. 
CONTROL: Finally, we compared the overall scores on the test items with control items in which the cause of the false belief remained present. Figure 5 shows a numeric trend towards a higher acceptability of control items in the present tense, but this was not substantiated by the statistical analysis in which ITEM TYPE (test, control) was included. A model with ITEM TYPE as a fixed factor and a random intercept and random slope of ITEM TYPE for PARTICIPANT and a random intercept for ITEM revealed no significant effect.

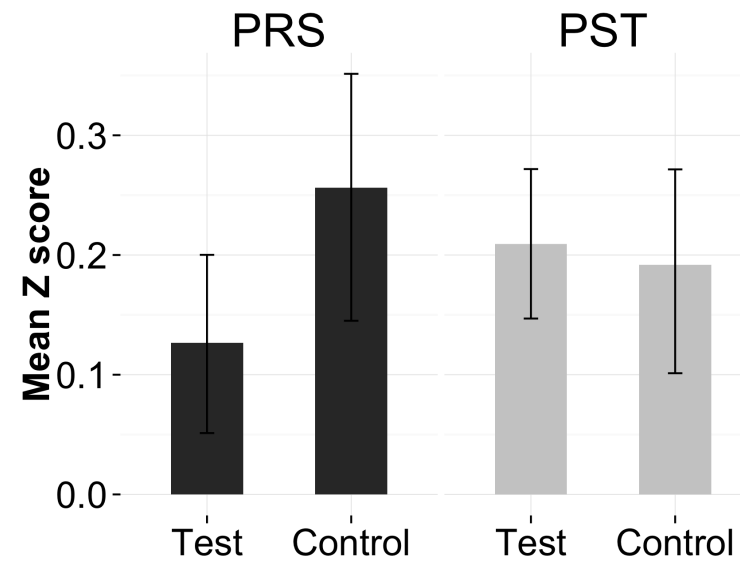

Figure 5: Mean z-scores of acceptability ratings from Experiment 1 for control items vs. test items, error bars show $95 \%$ CI.

The acceptability ratings from Experiment 1 were revealing of the acceptability of the present tense in the embedded clause. However, one might wonder if participants were inclined to inflate the acceptability of the present tense because they did not know the past tense was an explicit option within the same session. We wondered if participants would allow the present tense even when they were made aware that the past tense was available. We therefore conducted Experiment 2, using highly similar stimuli, but with a forced-choice behavioral measure, in which participants were asked to choose between present and past tense for the embedded clause. We reasoned that if participants chose the present tense even in such a task, when the past tense was a viable option, then this would be empirical evidence that the present tense was licensed. Moreover, if the preference was correlated with the manipulation of the target factors (duration of the property and who is aware of the false belief), then this would be evidence that such factors influence the felicity of present tense in the embedded clause.

\subsection{Experiment 2: forced choice task}

Participants 41 English speakers, all undergraduates at Rutgers University - New Brunswick, participated. As in Experiment 1, they were granted extra credit in a Linguistics or Cognitive Science course for participating. The age range of the participants was also 17 to 32 years. 
Stimuli The stimuli had the same structure as in Experiment 1. However, there were two minimal changes. First, since the matrix verb did not produce a significant main effect in Experiment 1 , the matrix verb was always tell. Second, participants were asked to choose between one of two target sentences at the end of the scenario: one with embedded present and the other with embedded past tense. Thus, the experiment had two within-subject factors (DURATION OF THE REPORTED PROPERTY (short-term vs. long-term)) and WHO WAS AWARE OF THE FALSITY (A: the reporter alone; B: the reporter and the reported speaker; C: the reporter, the reported speaker, and the audience)).

Procedure As before, the experiment began with a brief training session of three items to acclimate participants to the task. This time, data were presented on the Qualtrics platform online. Each subsequent aspect of the scenario was presented sequentially on the screen (see (5), yielding five windows of presentation). Participants pressed a 'next' button to advance through the scenario at their own pace. When presented with the target sentence, participants were asked to select the form of the embedded verb by choosing between a present and past tense form. The experimental session lasted approximately 25 minutes.

Results The binary data were analyzed using binomial generalized mixed effect models using the lmerTest package in R (Kuznetsova et al., 2015). Models were fitted with the maximal random effects structure justified by the data. Factors were entered into the model using sum coding. Figures show mean percentages of choice for the present tense. As for experiment 1 , we only report effects of individual factors, due to the complexity of the design and small numbers of items per condition.

DURATION OF THE REPORTED PROPERTY: This factor also turned out to have an effect on the choice for present tense in Experiment 2. Figure 6 shows a higher percentage of present tense for long-term properties $(M=62 \%)$ in comparison for short-term properties $(M=22 \%)$. This effect was signifcant in a model with DURATION as a fixed factor and random intercept and slopes for both PARTICIPANTS and ItEMS $(\beta=1.10, S E=.18, Z=6.2, p<.001)$.

WHO IS AWARE OF THE FALSITY: Figure 7 shows the results for this factor. There seems to be a numeric trend for a preference of present tense when only the reporter is aware of the falsity of the belief (Condition A). A statistical model with WHO IS AWARE OF THE FALSITY as a fixed effect and as a random slope for PARTICIPANT and ITEM only showed a trend towards significance $(p=.09)$. The same was obtained in a model using treatment coding. Even though condition $\mathrm{C}$ was significantly different from condition A $(p=.041)$ within the model, model comparison showed that the addition of the factor to a baseline model was only marginally so $(p=.07)$. This may reflect a power issue.

CONTROL: Finally, we compared the choice for present tense on the test items with that on control items in which the cause of the false belief remained present. Figure 8 shows no difference between the items and this was confirmed by the statistical analysis in which ITEM TYPE (test, control) was included. A model with ITEM TYPE as a fixed factor and a random intercept 


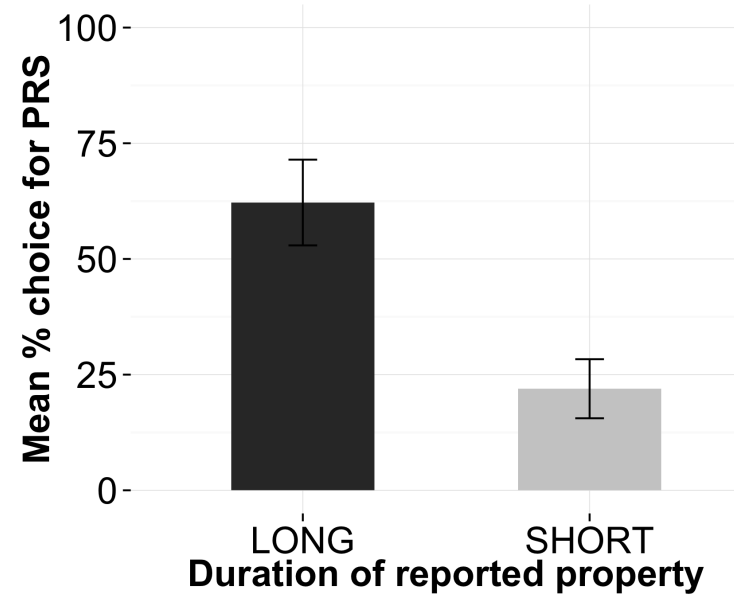

Figure 6: Mean percentage of choice for present tense in Experiment 2 for DURATION OF REPORTED PROPERTY, error bars show 95\% CI.

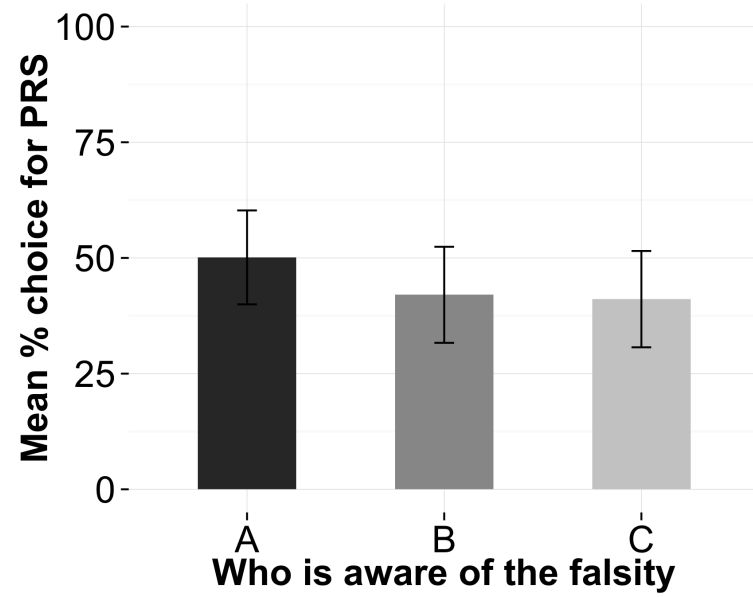

Figure 7: Mean percentage of choice for present tense in Experiment 2 for WHO IS AWARE OF THE FALSITY (A: the reporter alone; B: the reporter and the reported speaker; C: the reporter, the reported speaker, and the audience), error bars show 95\% CI. 
and random slope of ITEM TYPE for PARTICIPANT and a random intercept for ITEM revealed no significant effect.

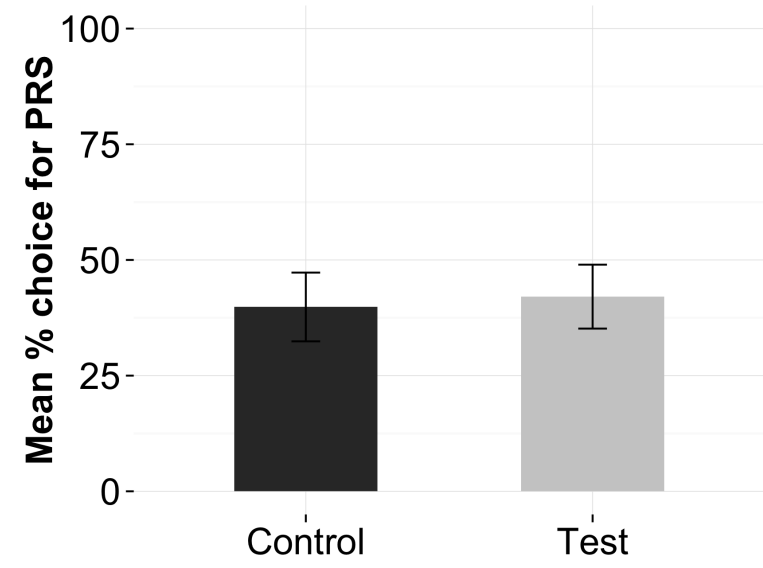

Figure 8: Mean percentage of choice for present tense in Experiment 2 for control items vs. test items, error bars show $95 \% \mathrm{CI}$.

\section{Discussion}

In the two experiments we have seen that when the cause of belief no longer holds, as in the Klecha-type example: (i) short term properties disfavor present tense and (ii) belief state of others seem to effect present tense use: present tense is better when people still entertain a false belief. (ii) is particularly interesting since it means that tracking other people's beliefs affects our choice of grammatical morphemes, even in the case of people who are not participating in the actual conversation. More research is needed to corroborate the effects of this factor.

Surprisingly, whether the cause of the false belief still holds - the key factor according to Ogihara-did not make a difference.

Why should this be? And how can we generalize over the various factors? For Costa (1972) and McGilvray (1974), the answer has to do with current relevance, an appealing notion since, after all, we are interested in the meaning of the present tense.

It seems possible to rephrase our findings as having to do with current relevance. The cause of the belief still holding at the actual utterance time (Ogihara's KEY OBSERVATION) is then just one of the ways in which the proposition expressed by the complement can still be relevant to the conversation the reporter is engaged in. Another way in which this proposition can be relevant at the time of the report is if the original audience still (falsely) believes it (factor (ii)). Yet another way could be cases where we do not expect changes to happen in the truth value of the proposition expressed by the complement between the reported time and the time of the report (i.e. the actual utterance time, $n$ ) (in line with in the category of eternal statements, a category mentioned in many textbooks of English, see Eckhardt 2001: p. 44 for an overview). This corresponds to factor (i), the duration of the reported property: for long-term properties (in 
our items usually individual-level properties) such a change is implausible: had the complement been true at the reported time it would still be true at the actual utterance time.

The challenge for de re analyses of tense noted in section 2 is to show how the determination of particular acquaintance relations - which concerns how an attitude holder became acquainted with a time/state-is sensitive to these factors. This is a challenge because it's unclear how the latter two factors above would matter for acquaintance: the second factor involves an audience whose beliefs may be independent of the attitude holder's beliefs, while the third factor involves counterfactual reasoning. While it is not out of the question that a richer, pragmatic theory of acquaintance relations could derive the factors above, it is not clear to us what such a theory would be like.

Another possibility is to provide an analysis of the embedded present tense that does not depend on acquaintance relations. While this would be a move away from the orthodoxy, ${ }^{5}$ we note that Klecha (in this volume) provides a glimpse of what such a move may be like. He proposes that semantically speaking, the use of the embedded present tense leads to ill-formedness when it is embedded under past, requiring pragmatic intervention to be rescued. According to Klecha, a double access interpretation is non-literal, a special kind of loose talk. While presenting the details of this analysis would take us too far a field, several comments are in order. Klecha's key idea is that present-under-past sentences can be felicitously used when "the temporal resolution in the discourse is sufficiently coarse so as to conflate the event time of the attitude verb with speech time; in other words, in discourses where the interlocutors don't care to make the distinction between event and speech time for the purposes of discussing what they're discussing." When the discourse is not sufficiently coarse, pragmatic enrichment via conflation of the speech time and the event time will not be triggered and infelicity will arise due to the Upper Limit Constraint (Abusch 1997).

This conflation between the event and the speech time could be an intriguing way to make sense of our factor (i) and perhaps even of the idea of current relevance in general. While more work is required to make sense of how exactly Klecha's proposed pragmatic enrichment is sensitive to the factors noted above, this task seems, on the face of it, promising. We leave this task open for further research. Our contribution here is a demonstration of how the applications of experimental methods may lead to important contributions to a theory of embedded tense, which must involve a sufficient pragmatic theory that complements the semantics. ${ }^{6}$

\section{References}

Abusch, D. (1988). Sequence of tense, intensionality and scope. In H. Borer (Ed.), Proceedings of WCCFL 7, pp. 1-14.

Abusch, D. (1994). Sequence of tense revisited: two semantic accounts of tense in intensional contexts. In H. Kamp (Ed.), Ellipsis, Tense and Questions. Dyana 2 Deliverable, pp. 87-139.

\footnotetext{
${ }^{5}$ Though in line with Hawthorne and Manley 2012, who argue that semantic theorizing should not involve acquaintance relations. See also Altshuler and Schwarzschild 2013; Bary and Altshuler 2014; Altshuler 2016, where an analysis of embedded tense is proposed without invoking de re mechanisms, though the analysis does invoke time concepts, viz. Heim 1994.

${ }^{6}$ See also Altshuler et al. 2015 for a corpus study that reaches the same conclusion by independent means.
} 
Abusch, D. (1997). Sequence of tense and temporal de re. Linguistics \& Philosophy 20, 1-50.

Altshuler, D. (2016). Events, States and Times. An essay on narrative discourse in English. Berlin/Warsaw: de Gruyter. Open access, available at: https://www.degruyter.com/view/product/474350.

Altshuler, D., V. Hacquard, T. Roberts, and A. White (2015). On double access, cessation and parentheticality. In S. D'Antonio, C.-R. Little, M. R. Moroney, and M. Wiegand (Eds.), Proceedings of Semantics and Linguistic Theory 25.

Altshuler, D. and R. Schwarzschild (2013). Correlating cessation with double access. In M. Aloni, M. Franke, and F. Roelofsen (Eds.), Proceedings of the 19th Amsterdam Colloquium, Amsterdam, pp. 43-50.

Bary, C. and D. Altshuler (2014). Double Access. In E. Csipak and H. Zeijlstra (Eds.), Proceedings of Sinn und Bedeutung 19.

Costa, R. (1972). Sequence of tenses in that-clauses. In P. Peranteau, J. Levi, and G. Phares (Eds.), Papers from the Eight Regional Meeting, pp. 41-51. Chicago Linguistic Society.

Cresswell, M. J. and A. von Stechow (1982). De re belief generalized. Linguistics and Philosophy 5, 503-535.

Eckhardt, S. E. B. (2001). Reported speech: empirical corpus findings compared with efl/esl textbook presentations. Master's thesis, Iowa State University.

Enç, M. (1987). Anchoring conditions for tense. Linguistic Inquiry 18, 633-657.

Hawthorne, J. and D. Manley (2012). The Reference Book. Oxford: Oxford University Press.

Heim, I. (1994). Comments on Abusch's theory of tense. In H. Kamp (Ed.), Ellipsis, Tense and Questions, Amsterdam, pp. 143-170. University of Amsterdam.

Klecha, P. (2015). Double access. Unpublished manuscript, University of Connecticut.

Klecha, P. (2018). A formal pragmatic account of double access. In Proceedings of Sinn und Bedeutung 22.

Kuznetsova, A., P. Bruun Brockhoff, and R. Haubo Bojesen Christensen (2015). lmerTest: Tests in Linear Mixed Effects Models. R package version 2.0-25.

McGilvray, J. A. (1974). A proposal for the semantics of tenses in English. Montreal Working Papers in Linguistics 1, 29-44.

Ogihara, T. (1995). Double-access sentences and reference to states. Natural Language Semantics 3, 177-210.

Smith, C. (1978). The syntax and interpretation of temporal expressions in English. Linguistics \& Philosophy 2, 43-99. 